\title{
Problem-based Learning Combined with Team-based Learning in Sports Biochemistry Courses
}

\section{-- The Application of Sugar Metabolism and Exercise Teaching}

\author{
Fangcheng Li \\ Sport Department, Northwest Minzu University, China \\ Fangcheng00336600@163.com
}

\begin{abstract}
Explore Problem-based learning (PBL) combining with Team-based learning (TBL) in sports biochemistry course sugar metabolism and movement section theory and experimental teaching, relative to the traditional teaching methods, the two method teaching makes students passive learning for active learning, increase the interest in learning, at the same time exercise their team spirit and active access to learn, improve their self-study ability, practical ability, scientific research ability, at the same time cultivate the consciousness of lifelong learning, the effect is remarkable.
\end{abstract}

Keywords: Problem-based Learning; Team-based Learning; Sports Biochemistry; Sugar Metabolism and Movement.

\section{Introduction}

Sports biochemistry is a basic required course in physical education, including the course with the metabolism and exercise of sugar, fat and protein, skeletal muscle metabolism regulation and energy utilization, sports fatigue recovery characteristics, acute and chronic exercise energy supply characteristics and other contents [1]. The concept of sports biochemistry is abstract, complex structure, various knowledge points, strong logic, sports students 'general professional foundation is weak, and the learning of sports biochemistry is somewhat difficult for them. The traditional teaching methods are relatively boring, and it is difficult to stimulate students' interest in learning. Through PBL combined with TBL and other teaching methods, the students can learn with problems, solve the problems in their actual life, stimulate their interest in learning, and exercise the importance of their teamwork, and play the role of supervision and supervision. This paper uses sugar metabolism and exercise for teaching, and discusses the application of PBL combined with TBL.

\section{Adopts the Teaching Method Introduced by Problems, and Guides the Students to Learn Actively and Establish the Teamwork Consciousness}

There are more concepts of sugar metabolism and exercise, including glycolysis, aerobic oxidation of sugar, sugar heterogenesis, the influence of sugar metabolism on exercise, etc. When explaining the problem, the first method introduced is adopted to guide students to explore the learning with problems. In view of the characteristics of sports major, we can lead to why can not always use 100 meters running speed to run 800 meters, in 5000 meters running, why can't always use 100 meters or 800 meters running speed, but the speed will be down. In the 100 meters running, 800 meters running, 5000 meters running, why do the legs feel the most painful when running 800 meters? Ask the above questions, let the students take the questions to preview, to find answers. At the same time, the class students 10 or 11 for a group, divided into four groups, with groups as the unit for learning, each group has a group leader, responsible for the learning situation of the students in this group. In the next class, you can randomly ask questions from the students of each group to answer the above questions, and the students of that group can answer them, and the results can be used as the usual results of the students of this group. This can encourage them to study hard, and at the same time because they are a team, if they do not work hard will affect the performance of all people of the group, so they will urge all students to study hard and play a role in supervising learning [2]. 


\section{Explains the Course Content and Answers Questions According to the Students Preview Combined with a Variety of Teaching Auxiliary Equipment}

The basic concepts of sugar classification, overview and other and so on can be roughly explained, students generally master through preview, the difficulties in this chapter are mainly the catabolism of sugar, the impact on exercise, gluconeogenesis, etc. Use multimedia and other teaching software to explain the concept of anaerobic glycolysis and aerobic oxidation of sugar. A molecule of glucose goes through anaerobic glycolysis in cell fluid, and 2 analysis of ATP,. If a molecule of glycogen passes through anaerobic glycolysis process in cell fluid, 3 analysis of ATP, generates 2 molecules of lactic acid, which can show each step of chemical reaction with PPT. The resulting lactic acid in the skeletal muscle, the $800 \mathrm{~m}$ full out running mainly uses anaerobic glycolysis to provide energy, so you feel the most sore in the $800 \mathrm{~m}$ full out running. Answer the questions raised before class. Oxygen oxidation of sugar, a molecule of glucose after a series of transformations, in sufficient oxygen, after the tricarboxylic acid cycle, finally completely oxidized to carbon dioxide and water, net generation 32 (30) molecule ATP, one molecule glycogen through aerobic oxide net generation 33 (31) molecule ATP, can see, a molecule of glucose (glycogen) through aerobic oxidation than through anaerobic glycolysis to produce ATP. However, this aerobic oxidation takes a long time, so a long time of exercise, relying on oxygen oxidation to provide energy, but the efficiency of the energy output is relatively low, so most of the time is relatively slow. The 100 meters running the fastest, it mainly relies on the existing ATP and $\mathrm{CP}$ (phosphate creatine in our muscles) to provide energy, due to their high efficiency of output energy, they can give them ATP and CP provide energy chemical reaction, you can see that ATP can release energy just one-step, and CP release energy after two-step reaction, so they provide energy efficiency is particularly high, but they content less in the body, so the energy time is relatively short. The $800 \mathrm{~m}$ and $5,000 \mathrm{~m}$ starts also rely on ATP and CP to provide energy, but then, the $800 \mathrm{~m}$ running relies on anaerobic glycolysis, and the 5,000 m running relies on oxygen oxidation of sugar. The output energy of anaerobic glycolysis is lower than ATP and CP, the oxygen oxidation output energy of sugar is lower than anaerobic glycolysis, but the output energy is more than them, so it can provide long-term sports projects, such as 5,000 meters running, because the aerobic oxidation of sugar has no lactic acid production, so mainly rely on the oxygen oxidation of sugar to provide energy of 5000 meters running, after exercise not like running 800 meters. The explanation in the process of the relevant concept, chemical reaction process and movement, help students solve the problems encountered in real life, which can stimulate students' interest in learning, change passive learning into active learning, make students learning interest higher, feel sports biochemistry course is no longer bitter concept and chemical reaction process, but close contact with life, can help solve the problems in life. At the same time, in the process of explaining the world famous athletes 800 meters full running sports performance and their sports adaptability. The accumulation of lactic acid makes muscle pain, but long-term lactic acid stimulation, can make muscle produce certain adaptation, long-term past, muscle acid resistance will increase, so the world famous athletes is because after long-term sports training, increased lactic acid resistance, anaerobic glycolysis capacity increase, sports performance increase too. Then, why after 800 meters running, after a few minutes, the muscles are not sore. Where did the lactic acid go, the original lactic acid can be directly oxidized to produce carbon dioxide and water, the more likely it is to be oxidized in the exercise state, the higher the proportion of oxidation. Lactic acid can also be eliminated through a series of metabolic pathways such as sugar or synthesis of other substances. Referring here to the concept of gluconeogenesis, the process of converting non-sugar substances to sugar is called gluconeogenesis, which is also clearly explained. After the end of the exercise, in order to accelerate the elimination of lactic acid, to walk slowly, can not sit still, is conducive to sports recovery. After most students finish strenuous exercise, they directly sit down and are no longer willing to walk, see the elimination of lactic acid, they can understand the principle, and will pay more attention to it in their later exercise. 


\section{Problem Introduction Method and Teamwork Method are Applied in Experimental Teaching to Improve Students ' Research and Exploration Ability and Teamwork Spirit}

Sports biochemistry is a strong practical course, must combine with experimental teaching to more clearly verify the textbook knowledge, at the same time through comprehensive and design experiments, improve students ' comprehensive use of textbook knowledge, combined with the actual movement, more in-depth scientific exploration and research, cultivate their scientific research ability. (1) Validation experiments use the sugar metabolism and movement content of this section, and the experiments involved are mainly the determination of blood lactic acid and blood sugar. These two tests mainly exercise students ' ability of basic experimental operation and use spectrophotometric method. Students need to learn to use spectrophotometry, centrifuges, water bath cookers, etc. This mainly adopts the way of teamwork for teaching, students need to preview the experimental content in advance, write the preview experimental report, after class or take random questions, ask the experimental principles, experimental methods, etc., and then as the usual results in the group, also do the group supervision and learn from each other. Through the above experiments, the theoretical knowledge is verified, while the learned knowledge is consolidated. The final experimental report and the performance of the experimental operation process can be used as the experimental results. (2) After basic experiments, the students have basically mastered the basic operation methods of the experiment and can carry out design experiments. Questions can be raised about sports that use anaerobic glycolysis to provide energy, such as 800 meters of lactic acid. lactic acid enters the blood through the blood and becomes blood lactic acid. The concentration of blood lactic acid in the body can be judged by measuring blood lactic acid. Also after running 800 meters to running, sports performance is different, is the concentration of blood lactic acid in the same, high exercise performance, high blood lactic acid concentration is high; the same sports performance, the development potential of high blood lactic acid concentration is higher or low development potential of blood lactic acid concentration is higher? With these problems, each group of students are experimental design, the designed experiment process to the teacher, the teacher to help them review, put forward modification opinions, until can smoothly develop the experiment, students use the class time and laboratory open time, experimental test, the teacher can teach the students to use lactic acid analyzer test method, which is conducive to them quickly carry out the blood lactic acid test. Students can take their own 800 meters running test, record results and test blood lactic acid concentration at the same time. Each group wrote experimental reports according to its own experimental process and experimental results as part of its experimental results. Finally, the teacher conducted experimental analysis and answers. According to the test results, according to the results of each group test, 800 meters to run at the same time of blood lactic acid test, sports performance is better, and blood lactic acid concentration is low, can also have higher performance space, his results, low blood lactic acid concentration, prove that his acid resistance is better, later continue to training, can improve the results. If the exercise performance is basically close, then the lower the blood lactic acid concentration, the greater potential to improve performance in the future, because his acid resistance ability can continue to improve, then the stronger his ability to use anaerobic glycolysis for energy supply. The above through design experiments, exploration and research, cultivate the students ' exploration spirit and practical ability, with problems to experiment, improve their interest in experiment, the students also feel that through the experiment a lot of harvest, consulted a lot of data to experiment. Team cooperation to carry out experiments and exercise their team awareness. Each team member should work harder to study, participate in every link, can not drag the team back, and urge them to learn more actively [3-4]. 
Volume 3 (2021)

\section{Summary}

Through the use of teaching methods including PBL and TBL, glucose metabolism and sports are taught. Compared with the traditional teaching methods, PBL improves students ' interest in learning, changes passive learning into active learning, and solves the problems encountered in students' actual sports. Some concepts, chemical reaction style, reaction principles of sports biochemistry are no longer so boring, no longer cramming teaching makes them feel relaxed, and the content of this teaching method of learning is longer memory. The TBL cultivates students 'teamwork spirit. In the process of design experiment, students' division of labor and cooperation, took the initiative to consult various materials with problems, and exercised their ability of independent thinking, practical ability and scientific research ability. At the same time, the students ' awareness of lifelong learning is cultivated, and the teaching effect is remarkable.

\section{Acknowledgments}

Identify applicable funding agency. Basic Scientific Research Business Expenses of Central Universities in 2018 (31920180037).

\section{References}

[1] Yunkun ZHANG, Shuzhe DING, Sports Biochemistry, Higher Education Press, August 2014.

[2] Xuefeng WANG, Chun-xiang QU, Chao LIU, and Yu-guan ZE, Reforming of teaching methods for biochemistry: exploring questions, solving problems, and achieve scores based on group's collaboration, Journal of Biology, Vol. 32, December, 2015, pp 122-123.

[3] Shawn R. Simonson. Making students do the thinking: Team-based learning in a laboratory course. Journal Advances in Physiology Education Volume 38, Issue 1. 2014, pp 49-55.

[4] Zhumei Sun, Tingjie Ye, Xiaofeng Yan, and Lu Wang, The Application of Team Based Learning in "Cell Differentiation, Aging and Death" Sections, Chinese Journal of Cell Biology, Volume 34, 2012, pp 911 915. 